\title{
Scientific analysis of tie luo, a Qing Dynasty calligraphy artifact in the Palace Museum, Beijing, China
}

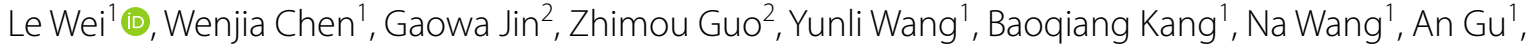 \\ Yun Zhang ${ }^{1}$ and Yong Lei ${ }^{1^{*}}$
}

\begin{abstract}
Tie luo (affixed hanging) was an expressive form of traditional Chinese calligraphy or paintings, and popular in the imperial palaces for interior decorations in Qing Dynasty (1644-1911 C.E.). A piece of calligraphic tie luo, written by an eminent calligrapher Gu Gao (1763-1832 C.E.), was restored recently in the Palace Museum, Beijing, China. The paper with pigment coating specially made for this calligraphic piece was named as fenjian. This article presented results from materials identification prior to the restoration. Multianalysis with scientific approaches revealed how tie luo was manufactured. It could be concluded that the investigated tie luo used a paper made from bast fibers of mulberry trees. And the decorative ground layer for the piece was also studied, which indicated that a type of organic red pigments were used for the masterpiece. White lead was considered as the main pigment, mixed with a red dye extracted from sappanwood. Meanwhile, animal glue, drying oils and beeswax were confirmed as the organic binding media. In dye analysis, protosappanin B and brazilin as well as brazilein were identified, which implied that sappanwood was used for the organic manufacture of pigments. In addition, both Nowik type $A$ and $C$ were found in the research, which were characteristic of sappanwood for identification.
\end{abstract}

Keywords: Tie luo, Affixed hanging, Calligraphy, Pigment coating, Fenjian, Sappanwood

\section{Introduction}

It is well known that Chinese papermaking contributed greatly to the development of global civilizations. Newly sheeted papers are usually natural white, even without being further processed (such as coating). But with the advance in papermaking technology, fenjian ( 粉笺), a type of multicolored paper, was manufactured to serve special purposes [1]. Such an achievement in color control for different functional papers has probably stimulated the development in decorative arts as well as calligraphy in China. Meanwhile, the pursuing of arts, the social status, some important events, etc. would have influenced the decision-making in selecting papers with the proper colors. However, prior to the current research,

\footnotetext{
${ }^{*}$ Correspondence: leiyongleo@hotmail.com

${ }^{1}$ Conservation Department, The Palace Museum, \#4 Jingshan Qianjie, Beijing 100009, People's Republic of China

Full list of author information is available at the end of the article
}

it remained unclear how pigments were coated to adjust their colors in ancient China. Then the study to reveal the manufacture of paper-based materials is very significant in the arts, economics, politics and science history fields. Fenjian was mentioned in early stage of China since Jin Dynasty (265-420 C.E.) followed by extensive reports of multicolor [2]. Little research clarified its composition and manufacture so far, though some limited scripts documented that the related papermaking technology had well developed historically.

Tie luo (贴落), known as 'affixed hanging', is a typical traditional Chinese calligraphy or paintings that are often bound with a strip of fabric around edges or straightly mounted to the wall. Literally it could be attached or dismounted as needed; and it was mainly produced in Qing Dynasty (1644-1911 C.E.) for interior decorations of imperial palaces [3]. In order to achieve the expression artistically, the writing paper usually used different kinds of processed paper. In this article, a piece of calligraphy 
tie luo is studied for its materials and making technique identification before its restoration. Specifically, the paper for the whole piece was actually the fenjian as mentioned above. In order to minimize the destruction to the masterpiece when sampling, we only took rough fiber paper from the lowest layer of paper for the fiber identification and pigment analysis. Optical microscopy $(\mathrm{OM})$ and polarizing light microscopy (PLM) were used to observe microscopic morphology of paper fiber and particle distribution of red pigments on the paper surface. X-ray diffraction (XRD) was applied to provide the possible mineralogical information. Micro-Fourier transform infrared spectroscopy (Micro-FTIR) combined with pyrolysis gas chromatography and mass spectrometry with thermal assisted hydrolysis and methylation (THMPy-GC/MS) were together utilized to characterize and identify the main pigments and organic binding media. Ultra-performance liquid chromatography-quadrupoletime-of-flight mass spectrometry (UPLC-Q-TOF-MS) revealed the source of coloring matter. The manufacture was tentatively discussed on the basis of analytical results. The present study offers insight into the manufacture of fenjian, as well as the use of natural dyes, in ancient China.

\section{Material}

This piece of calligraphy tie luo $(132.5 \mathrm{~cm} \times 42 \mathrm{~cm}$, Fig. 1a) was written by an eminent calligrapher Gu Gao (顾睡, 1763-1832 C.E.) [4]. The special paper for this piece used the fenjian with colored pigment coating. The piece was kept in the Building of Auspicious Clouds (吉 云楼) in the northern part of the Garden of Compassion and Tranquility (慈宁宫花园) in the Palace Museum, Beijing, China. The meaning of this calligraphy is to praise the political ruler for prosperity and hope the people live in peace.

Surrounding the calligraphic Chinese words, flowers, bamboo leaves and other patterns were block-printed as decoration. Before removing the blue side fabric, the whole ground didn't look like having special color decoration. However, once detaching the strip, a narrow edge underneath (Fig. 1b) was more reddish than other area uncovered possibly due to different light fading speed [5, 6]. The obvious traces of painting brush with parallel red lines could be observed on the back side (Fig. 1c). After a careful investigation, the whole piece (Fig. 1d) had four layers of paper including a layer for painting and three layers of supporting paper (a lining of fine fiber paper and another two layers of rough fiber paper). Many reddish
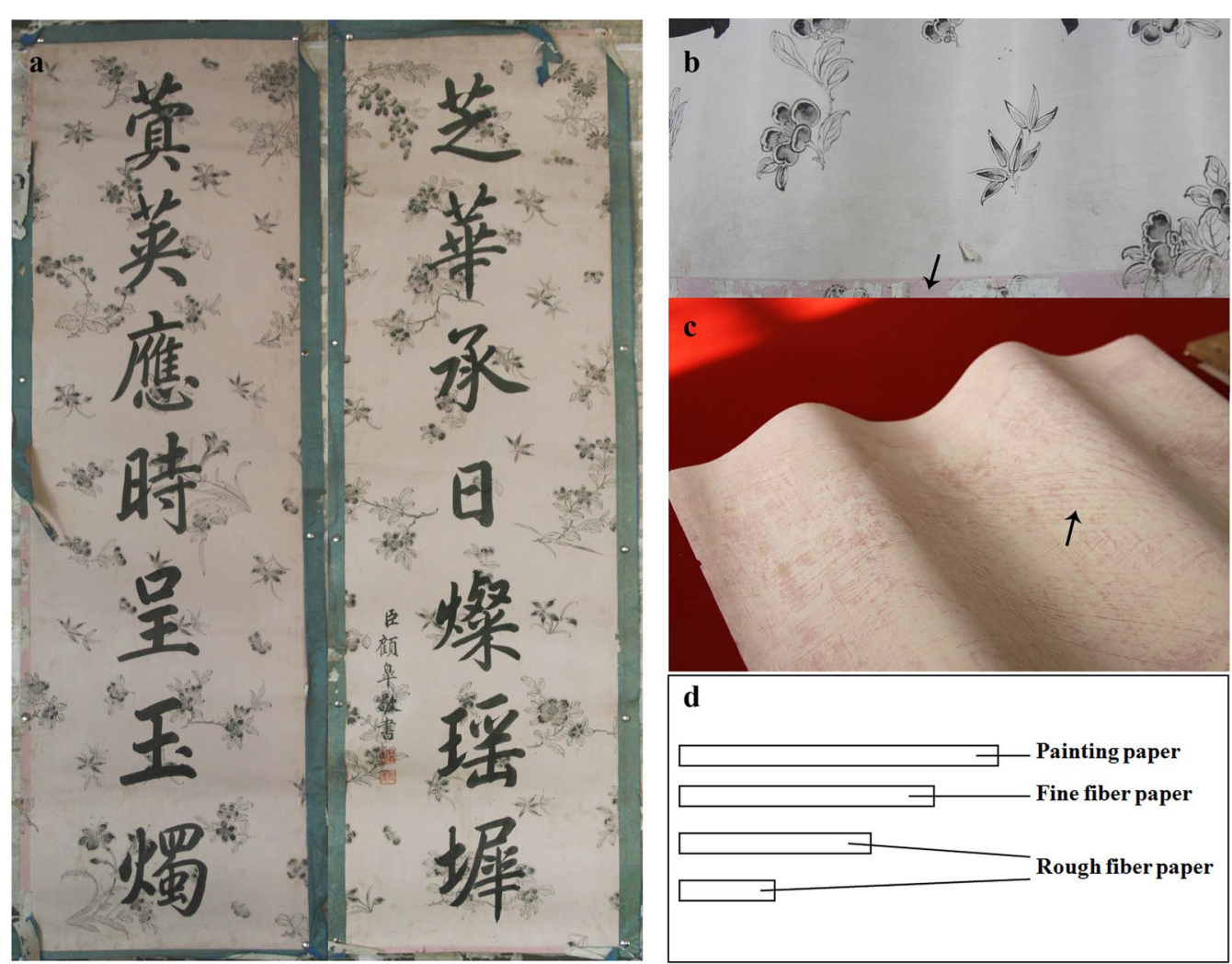

Fig. 1 A piece of tie luo in the Palace Museum has writings handwritten by Gu Gao. a Original appearance of the tie luo; $\mathbf{b}$ a narrow edge underneath with no fading trace; $\mathbf{c}$ traces of reddish pigment on the paper back; $\mathbf{d}$ schematic structure of the whole piece 
pigment powders could be also identified on each layer of the supporting paper underneath the painting layer.

\section{Methods}

Firstly we observed the paper fiber and surface pigment distribution with OM and PLM, and apply XRD to confirm the mineralogical compositions of fenjian. Then we used the FTIR combining with Py-GC/MS to identify the surface pigments and organic binding media. We combined UPLC and high resolution Q-TOF-MS together to identify the organic dyestuff. The specific materials and instruments were listed below.

\section{Observation of paper fiber and surface pigment distribution}

To identify the paper fiber and specific pigment, we conducted the microscopic observation with OM and PLM. Paper surface reddish pigments which were collected carefully with a scalpel and paper fiber were observed respectively with Leica DM4000M and DM4500P microscope both equipped with AnalySIS Auto digital imaging software at different magnifications $(5 \times, 10 \times, 20 \times$, $40 \times, 63 \times)$. Zinc-based Herzberg reagent was used to dye paper fiber. The preparation method was as follows according to Li's research [7]. Zinc chloride (20 g) dissolved in distilled water $(10 \mathrm{~mL})$ to form the solution A, and potassium iodide $(2.1 \mathrm{~g})$ and iodine $(0.1 \mathrm{~g})$ dissolved in distilled water $(5 \mathrm{~mL})$ to form the solution $\mathrm{B}$. The supernatant was ready to use after mixing the solution A and B overnight.

\section{Mineralogical compositions of reddish pigments}

To confirm the mineralogical compositions of surface pigments from fenjian, we carried out XRD experiment on Rigaku D/Max 2550PC diffractometer operating with $\mathrm{Cu} \mathrm{K \alpha}$ radiation $(40 \mathrm{kV}, 150 \mathrm{~mA})$ at a scan rate of $8^{\circ} \%$ $\mathrm{min}$ in the range from $3^{\circ}$ to $90^{\circ}$. Phases in pigments were identified by comparing their XRD patterns to those in the Joint Committee on Powder Diffraction Standards (JCPDS) database.

\section{Reddish pigments and organic binding media analysis}

To identify the surface pigments and organic binding media, we used the FTIR instrument. Infrared spectra were obtained with Thermo Fisher, Nicolet iN10 Mx Fourier transform microscope infrared spectrometer with mercury cadmium telluride (MCT) detector. Two measurement modes were related including attenuated total reflection (ATR) mapping and micro transmission with diamond compression cell. The spectrum was composed of 64 scans and ranging from 4000 to $650 \mathrm{~cm}^{-1}$. The spectral resolution was about $4 \mathrm{~cm}^{-1}$ and the spectrum was analyzed with OMNIC Picta software.
The specific organic binding media were further analyzed by Py-GC/MS. The experiment was performed on Agilent, 7890B/5977A gas chromatography and quadrupole mass spectrometer combined with a Frontier, EGA-PY3030D pyrolyzer. A capillary column HP-5MS $(30 \mathrm{~m} \times 0.25 \mathrm{~mm} \times 0.25 \mu \mathrm{m})$ was used and the energy of electron ionization was $70 \mathrm{eV}$. According to the online methylation Py-GC/MS, less than $1 \mathrm{mg}$ of the reddish pigments and $5 \mu \mathrm{L}$ of $10 \%$ methanol TMAH (Aladdin) solution were placed in a sample cup, and then introduced into the pyrolyzer. The derivative reaction was accomplished while pyrolyzed. Pyrolysis temperature was set at $600^{\circ} \mathrm{C}$ for $0.2 \mathrm{~min}$ while the pyrolyzer interface was set at $300{ }^{\circ} \mathrm{C}$. The chromatographic conditions were: split injection, split ratio $50: 1,1.0 \mathrm{~mL} / \mathrm{min}$ of Helium (purity 99.995\%) as carrier gas and GC injector was held at $300{ }^{\circ} \mathrm{C}$. Initial temperature was $50{ }^{\circ} \mathrm{C}$ for $2 \mathrm{~min}$, with a gradient of $4{ }^{\circ} \mathrm{C} / \mathrm{min}$ up to $280{ }^{\circ} \mathrm{C}$ which was kept for $5 \mathrm{~min}$. The mass spectrometer was scanned ranging from 29 to $550 \mathrm{~m} / z$ in the full scan mode. The temperatures of MS ion source and MS quadrupole were set at 230 and $150{ }^{\circ} \mathrm{C}$ respectively. Mass spectra of the pyrolysis products were identified by using the NIST MS library and interpretation of the main fragmentations.

\section{Identification of organic dye separated from red pigments Extraction and sampling procedures}

To analyze the specific organic dyes, the extraction from matrix should be carried out at first. Reddish pigments and three traditional dye plants including munjeet, safflower and sappanwood were extracted with $0.1 \mathrm{M}$ $\mathrm{HCl}-\mathrm{MeOH}$ solvent (Fisher Scientific). The extraction solvents were improved according to the most common system Wouters reported [8]. About $40 \mathrm{mg}$ of pigments was weighted and transferred into a vial. $700 \mu \mathrm{L}$ of $0.1 \mathrm{M}$ $\mathrm{HCl}-\mathrm{MeOH}$ solution was added, after the ultrasonic extraction and centrifugation, the supernatant was concentrated. The condensation sample was redissolved in $200 \mu \mathrm{L}$ methanol solution for UPLC-Q-TOF-MS analysis.

\section{Liquid chromatography conditions}

To tentatively analyze the possible dye plant, we used ultra-performance liquid chromatography (UPLC) instrument. The chromatograms were obtained using Waters ACQUITY H-Class with photodiode array (PDA) detector and BEH C18 column $\left(2.1^{*} 100 \mathrm{~mm}, 1.7 \mu \mathrm{m}\right)$. The data were collected by Empower 3 software. The mobile phase was composed of water containing $0.1 \%$ formic acid (Aladdin) as solvent $\mathrm{A}$ and acetonitrile (Fisher Scientific) as solvent B. The gradient was 95\% A from 0 to $0.3 \mathrm{~min}, 95-5 \% \mathrm{~A}$ from 0.3 to $9.3 \mathrm{~min}, 5 \% \mathrm{~A}$ held for $1 \mathrm{~min}$, then 5-95\% A from 10.3 to $10.5 \mathrm{~min}$ and 
held at $95 \%$ A for $1.5 \mathrm{~min}$. The flow rate was $0.25 \mathrm{~mL} / \mathrm{min}$. Column temperature was $30{ }^{\circ} \mathrm{C}$. The UV detective wavelength was set from 190 to $800 \mathrm{~nm}$. The injection volume for the sample and the other reference natural dyes protosappanin B (National Institutes for Food and Drug Control) and brazilin (J\&K Scientific) as well as brazilein (adventitiously existed in brazilin) was $2 \mu \mathrm{L}$, respectively.

\section{Mass spectrometry}

High resolution MS measurements could give the characteristic components for dyestuff determination. The experiment was conducted by Waters Xevo G2-S Q-TOF mass spectrometer equipped with the electrospray ionization (ESI) ion source. Instrument control was performed using UNIFI software and data acquisition and processing were conducted using MassLynx software. MS spectra were acquired in negative mode. The scan range was from $m / z 50$ to 1200 . Other conditions were optimized as follows: source temperature, $120{ }^{\circ} \mathrm{C}$; cone voltage, $40 \mathrm{~V}$; capillary voltage, $2.5 \mathrm{kV}$; desolvation gas $\left(\mathrm{N}_{2}\right)$ flow rate, $800 \mathrm{~L} / \mathrm{h}$; nebulize gas flow rate, $10 \mathrm{~L} / \mathrm{h}$; desolvation temperature, $450{ }^{\circ} \mathrm{C}$; collision energy, 5-60 eV. Real-time calibration (every $30 \mathrm{~s}$ ) applied leucine enkephalin $(0.4 \mathrm{ng} / \mu \mathrm{L})$ as internal standard.

\section{Results and discussion}

\section{Microscopic examination of pigments and fibers}

The reddish pigments were taken from the front surface of the paper and the other side had some plaster residues from the interior wall (Additional file 1). The pigment particles were uniform in size and reddish (Fig. 2a). In the picture (Fig. 2b) taken by polarized light microscope (PLM) the reddish powder showed no apparent extinction phenomena under orthogonal polarization, which indicated that some organic dye be used for the manufacture of pigments. PLM alone does not suffice to confirm the presence of organic dyes [9]; LC-MS was then considered as appropriate to analyze organic dyes or

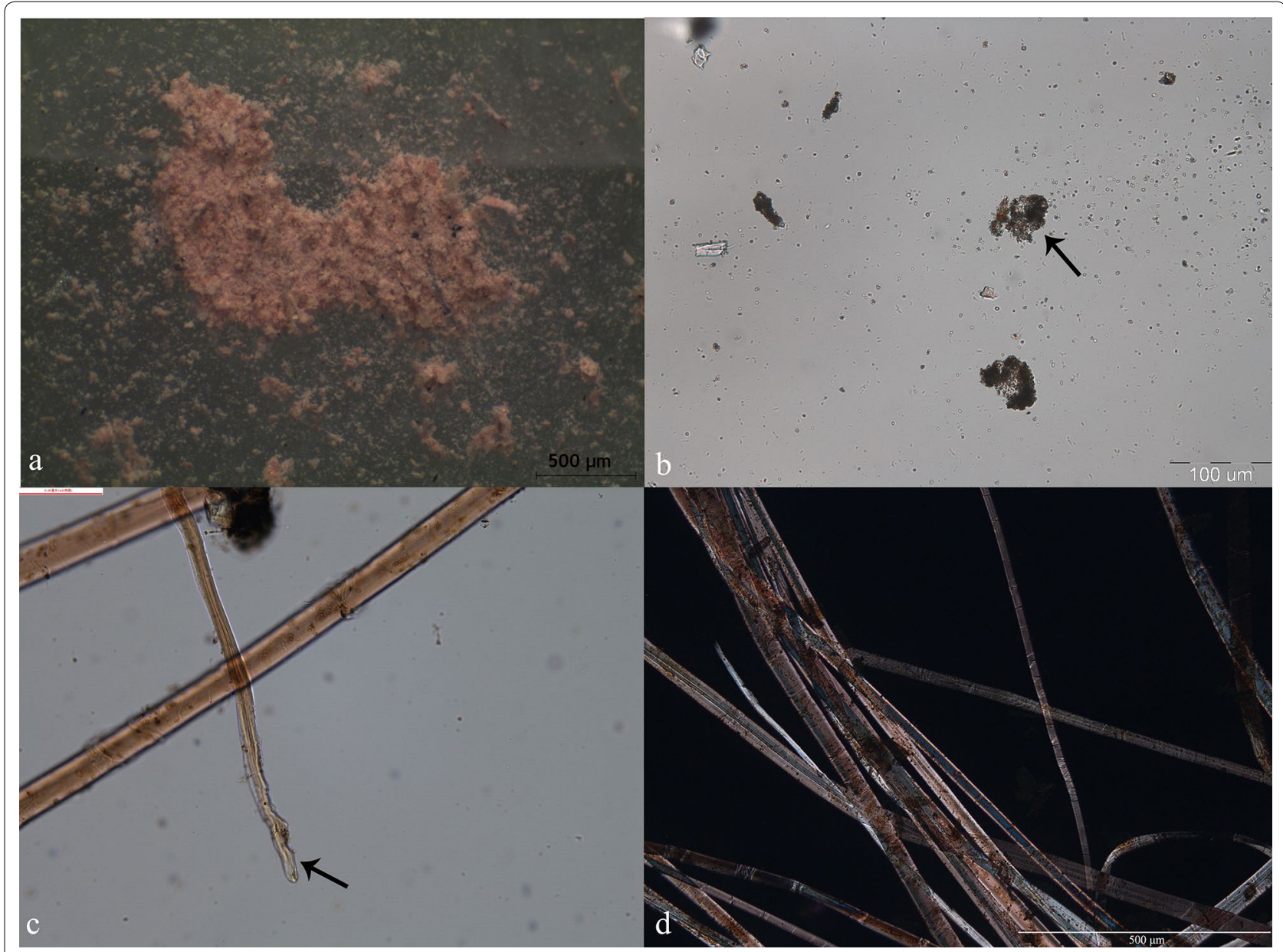

Fig. 2 The pigments and fiber images. a morphology of scraped reddish pigments; $\mathbf{b}$ plane-polarized light image of reddish pigments, indicating some organic dye used for the manufacture of pigments (arrow); $\mathbf{c}$ morphology of the fiber, a transparent gelatinous membrane at the end of fiber (arrow) indicating mulberry fiber; $\mathbf{d}$ crossed polarized light image of microscope, nodes in the lower left indicating mulberry bast fiber image 
pigments [8]. The microscopic observation of paper fiber was more apparent with Herzberg reagent as shown in Fig. 2c, d. The bast fibers could be identified because of the salient features of the transverse dislocations (nodes) and narrow cell lumens. The fiber showed a reddish brown or some wine red color by stains visually. Accordingly, the content of lignin in different types of fibers significantly influenced the stained color. The mulberry in which the content was about $8-15 \%$ of dry weight, seemed more possible to contribute that color [7]. Besides, there was a transparent gelatinous membrane enveloping at the end of fiber further to prove the existence of mulberry (paper mulberry or mulberry bark). Through the fiber measurer, fiber width ranged from 22 to $43 \mu \mathrm{m}$ and the average fiber length was about $20 \mathrm{~mm}$, which were in accordance with the fiber characteristics of mulberry bark [10]. In addition, we did not detect the calcium oxalate crystals further to rule out the possibility of paper mulberry. As a result, the fiber was very likely sourced from mulberry trees.

\section{Mineralogical compositions}

The results of XRD analysis (Fig. 3) showed there were four phases in the pigments including cerussite $\left(\mathrm{PbCO}_{3}\right)$, hydrocerussite $\left(\mathrm{Pb}_{3}\left(\mathrm{CO}_{3}\right)_{2}(\mathrm{OH})_{2}\right)$, anglesite $\left(\mathrm{PbSO}_{4}\right)$ and aragonite $\left(\mathrm{CaCO}_{3}\right)$. Natural lead carbonate was found and usually accompanied by the basic carbonate in X-ray diffraction detection [11]. In the history of painting, the emergence of $\mathrm{PbSO}_{4}$ reported in literature exhibited quite a long period as well as a very broad area in the world. It was considered as degradation products of lead-based pigments reinforced by several factors such as atmospheric pollution, humidity and temperature variations $[12,13]$. Also, there was another possible reason for the formation of $\mathrm{PbSO}_{4}$. The alum gelatin solution was often used as the binding media in the mounting of the typical traditional Chinese calligraphy or paintings. The $\mathrm{PbSO}_{4}$ could be formed during the painting and mounted process. The cerussite or hydrocerussite reacted with the alum to form the anglesite because the humid in the pigment layer and the paper were very high. Calcium carbonate as a common filling pigment was mixed in white

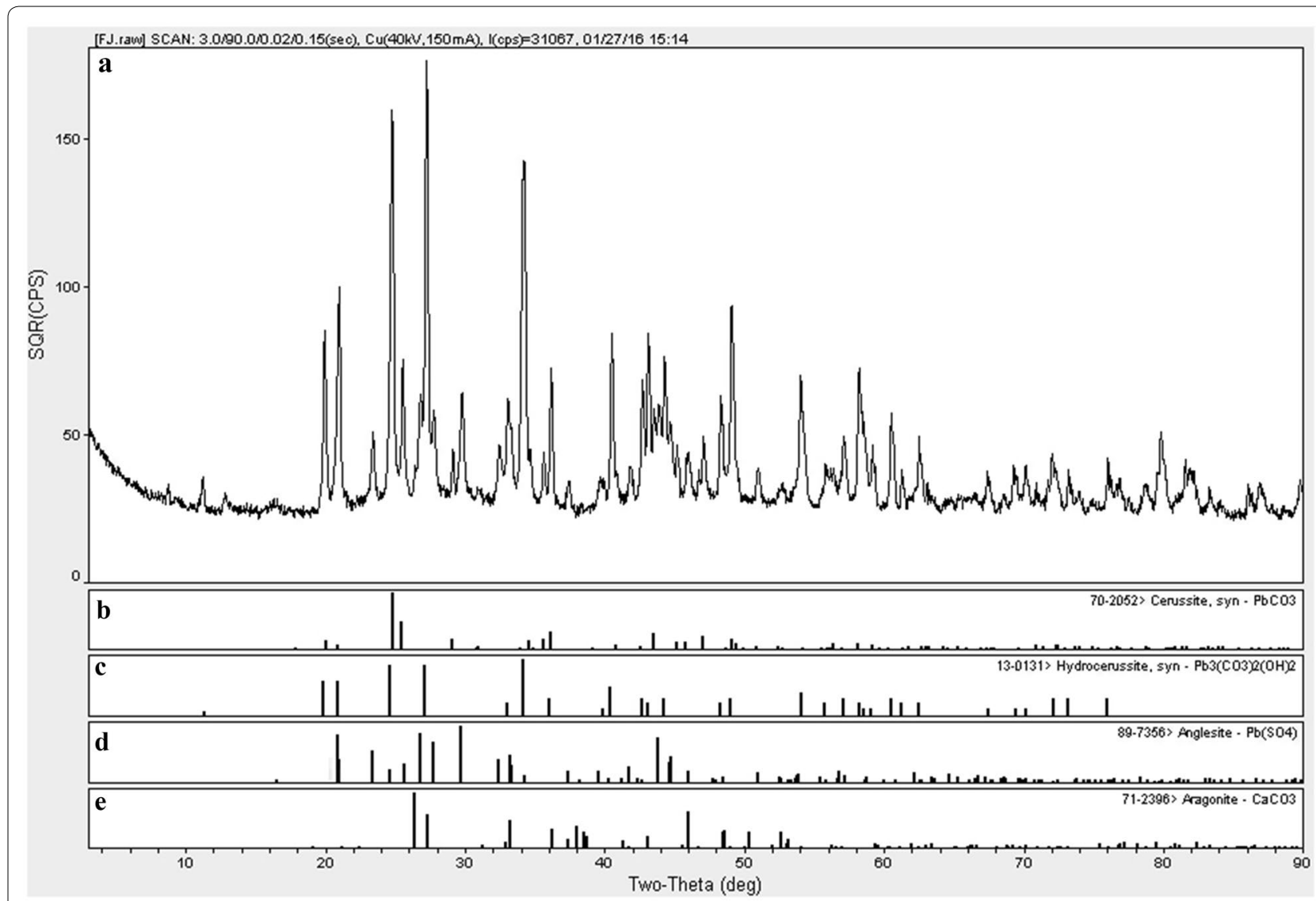

Fig. 3 XRD patterns of reddish pigments (a) and database standard of cerussite $\left(\mathrm{PbCO}_{3}, \mathbf{b}\right)$, hydrocerussite $\left(\mathrm{Pb}_{3}\left(\mathrm{CO}_{3}\right)_{2}(\mathrm{OH})_{2}, \mathbf{c}\right)$ anglesite $\left(\mathrm{PbSO} \mathrm{H}_{4}\right.$, d) and aragonite $\left(\mathrm{CaCO}_{3}, \mathbf{e}\right)$ 

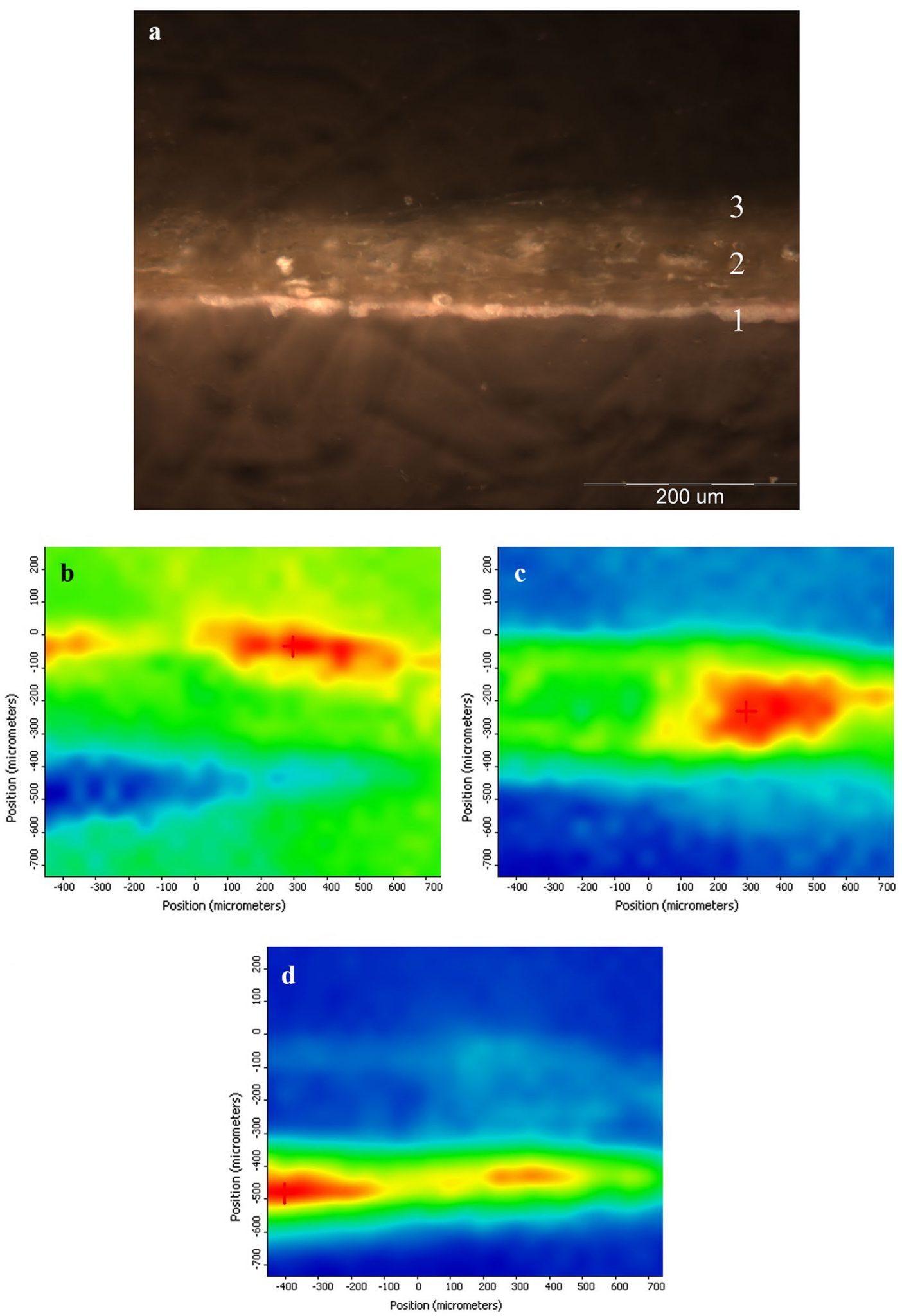

Fig. 4 ATR-FTIR chemigraphy mapping of fenjian. a ATR photomicrograph on cross section of fenjian ( $\times 50$ magnification); b pigment layer mainly contained white lead (located in no. 1, $1415 \mathrm{~cm}^{-1}$ ), c paper fiber (located in no. 2) consisted of cellulose $\left(1100-1000 \mathrm{~cm}^{-1}\right)$; d ground ash (located in no. 3) indicated the existence of talc $\left(3674 \mathrm{~cm}^{-1}\right)$, lime $\left(1405,876 \mathrm{~cm}^{-1}\right)$ and clay minerals $\left(1021 \mathrm{~cm}^{-1}\right)$. Blue and red represent lower and higher concentration respectively 
Table 1 Characteristic Infrared Bands on the fenjian

\begin{tabular}{lll}
\hline Location no. & Materials & $\begin{array}{l}\text { Characteristic infrared bands } \\
\left(\mathbf{c m}^{-\mathbf{1}}\right)\end{array}$ \\
\hline 1 & $\mathrm{~Pb}_{3}\left(\mathrm{CO}_{3}\right)_{2}(\mathrm{OH})_{2}$ & 353714151046681 \\
& $\mathrm{PbCO}_{3}$ & 1415839 \\
& $\mathrm{CaCO}_{3}$ & 1415873 \\
& $\mathrm{PbSO}_{4}$ & 1110672 \\
& Binding medium & 335029202850173616501540 \\
& Cellulose & 111110601036 \\
& Animal glue & 16421428 \\
& Talc & 3674 \\
& Lime & 1405876 \\
& Clay & 1021 \\
\hline
\end{tabular}

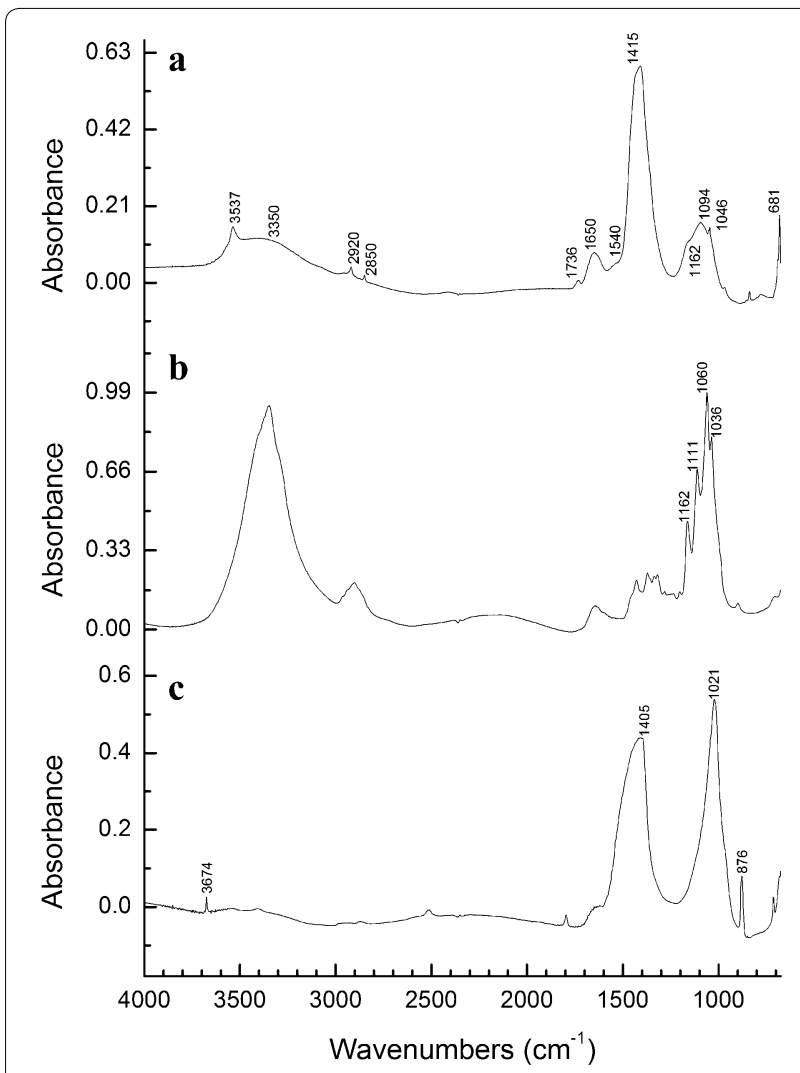

Fig. 5 Micro-FTIR absorbance spectra of fenjian in different locations. Reddish pigments (a), paper fiber $(\mathbf{b})$, ground ash (c)

lead to reduce the costs and improve the mechanical properties of the pigments [14].

\section{Identification of pigments and organic binding media}

ATR-FTIR was used to confirm the variety of the pigments and organic binding media. Cross section of the thick fiber paper from the lowest layer of the whole tie luo with polyester resin presented one layer of pigments over the paper fiber and identified with the visual observation in Fig. 4. Table 1 showed the characteristic vibration bands of different locations.

Micro-FTIR absorbance spectra of fenjian were shown in Fig. 5. The characteristic peaks of paper fiber (Fig. 5b) consisted of cellulose (1100-1000 $\mathrm{cm}^{-1}$ ) and aluminium (detected by XRF in Additional file 2) additive in the animal glue was one possible cause of shoulder cellulose band [15]. ATR measurement of ground ash (Fig. 5c) indicated the existence of talc $\left(3674 \mathrm{~cm}^{-1}\right)$, lime $(1405$, $\left.876 \mathrm{~cm}^{-1}\right)$ and clay minerals $\left(1021 \mathrm{~cm}^{-1}, \mathrm{Si}-\mathrm{O}\right.$ asymmetrical stretching vibration) [16] as the possible plaster residues from the interior wall.

Infrared \& Raman Users Group (IRUG, http://www. irug.org) database showed that the main component of the reddish pigments (Fig. 5a) was basic white lead. It was a very useful white pigment as base and could be applied in painting with various organic dye tints [11]. Two mineral phases, cerussite $\left(\mathrm{PbCO}_{3}\right)$ and hydrocerussite $\left(\mathrm{Pb}_{3}\left(\mathrm{CO}_{3}\right)_{2}(\mathrm{OH})_{2}\right)$, were the main composition of basic white lead [17]. In the fingerprint region at 1500 $650 \mathrm{~cm}^{-1}$, the peaks occurring at 1415, 1046, $681 \mathrm{~cm}^{-1}$ corresponded to the strong stretching vibrations of $\mathrm{CO}_{3}{ }^{2-}$ for neutral lead carbonate (cerussite), calcium carbonate (aragonite) and basic lead carbonate (hydrocerussite), the weak absorbance band near $3537 \mathrm{~cm}^{-1}$ was attributable to $\mathrm{OH}$ stretching for the latter $[13,18]$. The strongest absorbance band near $1415 \mathrm{~cm}^{-1}$ suggested the presence of more than one carbonate [9]. The three $\mathrm{C}-\mathrm{O}$ bands at 1162, 1094 and $1046 \mathrm{~cm}^{-1}$ occurred in a maple leaf pattern were characteristic of drying oils; moreover, because of containing ester group, the absorbance peak of $\mathrm{C}=\mathrm{O}$ appeared at ca. $1736 \mathrm{~cm}^{-1}$ [19]. While combining with other characteristic peaks of $2920,2850 \mathrm{~cm}^{-1}$ $\left(\mathrm{CH}_{2}\right), 1650 \mathrm{~cm}^{-1}$ (Amide I band) and $1540 \mathrm{~cm}^{-1}$ (Amide II band), the existence of organic binding medium was also proved which may be associated with protein, drying oils or the beeswax [20].

Py-GC/MS was applied for more information about the specific organic binding medium. Trace amount of reddish pigments were analyzed by Py-GC/MS using TMAH. Total ion chromatogram (TIC) was exhibited in Fig. 6. The identification marks on every peak were listed in Table 2 which corresponded to the characteristic pyrolysis products. Since online methylated technique was applied, methylation products were mainly detected.

Some components with nitrogen (no. $\mathrm{P}_{1}-\mathrm{P}_{8}$ ) demonstrated that protein materials were applied; furthermore pyrrole was detected as one characteristic component in animal glue marker [20], indicating the possible presence of gelatin as the source of animal glue. One important role of gelatin was to improve the hardness of the paper 


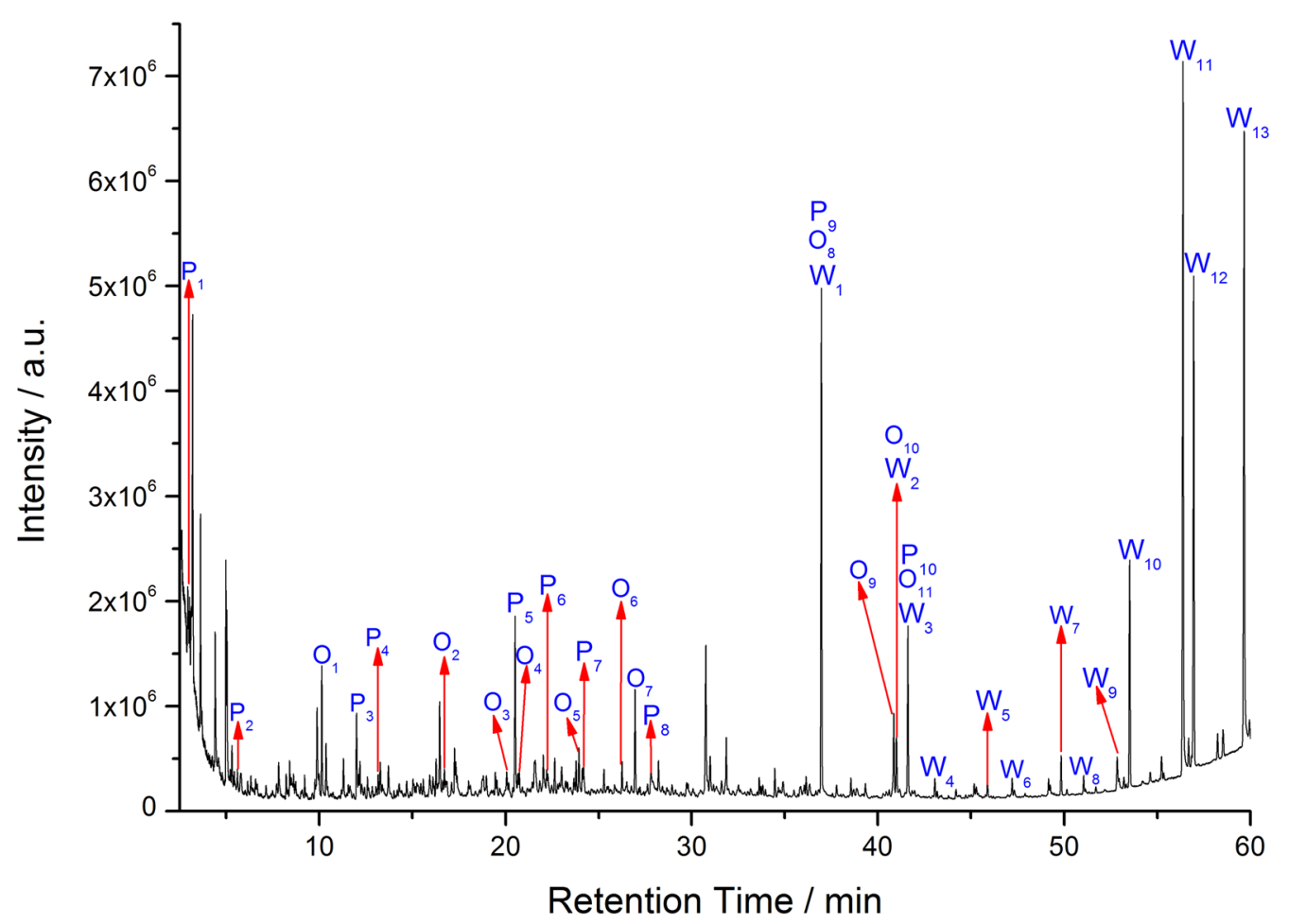

Fig. 6 Pyrogram of reddish pigments obtained by THM-Py-GC/MS indicating the use of animal glue (no. $\mathrm{P}_{1}-\mathrm{P}_{10}$ ), drying oils (no. $\left.\mathrm{O}_{1}-\mathrm{O}_{11}\right)$ and beeswax $\left(\right.$ no. $\left.W_{1}-W_{13}\right)$ as binding media

surface and fix the color [3]. Mono-carboxylic acids with the carbon number of $9,10,12,16,18$ (no. $\mathrm{O}_{2}, \mathrm{O}_{3}, \mathrm{O}_{6}, \mathrm{O}_{8}$ $\mathrm{O}_{9-11}$, respectively) and di-carboxylic acids with the carbon number of 4, 7, 8, 9 (no. $\mathrm{O}_{1}, \mathrm{O}_{4}, \mathrm{O}_{5}, \mathrm{O}_{7}$, respectively) were detected, especially the identification of azelaic acid (no. $\mathrm{O}_{7}$ ), indicating the presence of drying oils [21]. The purpose of drying oils used in the manufacture of fenjian was to protect the white lead pigment from blackening [11]. Benzene derivatives with the characteristic mass values of $\mathrm{m} / z$ 91 and 105 were not found in the pyrolysis results, indicating that there was no boiled tung oil.

In addition, a series of long-chain alkene, fatty acids and alcohols with carbon number more than 20 were detected in the retention time of 43-60 min, implying the existence of wax as coating additive in the manufacture of fenjian [22]. The relatively high content of tetracosanoic acid (no. $\mathrm{W}_{10}$ ) and hexacosanoic acid (no. $\mathrm{W}_{12}$ ) detected in the sample could be confirmed as beeswax [23] to increase the smoothness and brightness of the coating paper. Given that both the drying oils and wax had the palmitic acid and stearic acid, the often discussed eigenvalues of $\mathrm{P} / \mathrm{S}$ could not be used to identify the species of oils here [23]. Tung oil, linseed oil, walnut oil and poppy seed oil commonly used in ancient China were the possible sources, and the plant source of drying oils was needed to be further clarified in our future work.

\section{Dye identification of the reddish pigments from fenjian}

According to Han's research [24], red dyes used in Ming and Qing imperial decorations were usually extracted from safflower, sappanwood and munjeet. UPLC was used to tentatively analyze the extracts of reddish pigments and three plants. Base on the retention time and UV-Vis spectra, sappanwood was regarded as the possible dye plant. UPLC chromatograms of the extracts of reddish pigments and sappanwood and their characteristic UV-Vis spectra were exhibited in Fig. 7. Nowik type A (4.061 $\mathrm{min})$ and type C (4.921 $\mathrm{min})$ were found both in reddish pigment extract and sappanwood extract, which were colorless but characteristic components for identification. Nowik type A and $\mathrm{C}$ represented two different types of structural families, and each had the similar structure which contained a large number of compounds in UV-Vis absorbance spectra, yet to be identified [25]. They were very lightfast and often existed in sappanwood dyed samples although less influence the overall color [24]. 
Table 2 Characteristic pyrolysis products and assignment results of reddish pigments by THM-Py-GC/MS (the no. peak mark respectively corresponded to the pyrolysis product in Fig. 6)

\begin{tabular}{|c|c|c|c|}
\hline No. & $\mathrm{RT} / \mathrm{min}$ & Characteristic pyrolysis products & Assignment results \\
\hline P1 & 3.116 & Pyrrole & Animal glue \\
\hline P2 & 5.215 & 2,5-Dimethyl-1H-pyrrole & Animal glue \\
\hline 01 & 10.126 & Butanedioic acid, dimethyl ester & Drying oil \\
\hline P3 & 11.993 & 1-methyl-2,5-pyrrolidinedione & Animal glue \\
\hline P4 & 13.153 & Methyl 1-methylpyrrole-2-carboxylate & Animal glue \\
\hline $\mathrm{O} 2$ & 16.709 & Nonanoic acid, methyl ester & Drying oil \\
\hline $\mathrm{O} 3$ & 20.05 & Decanoic acid, methyl ester & Drying oil \\
\hline P5 & 20.514 & 1-Methyl-5-oxo-L-proline methyl ester & Animal glue \\
\hline $\mathrm{O} 4$ & 20.734 & Heptanedioic acid, dimethyl ester & Drying oil \\
\hline P6 & 22.262 & 1,3,5-Trimethyl-2,4(1H,3H)-pyrimidinedione & Animal glue \\
\hline O5 & 23.933 & Octanedioic acid, dimethyl ester & Drying oil \\
\hline P7 & 24.177 & Dihydro-1,3,5-trimethyl-2,4(1H,3H)-pyrimidinedione & Animal glue \\
\hline O6 & 26.252 & Dodecanoic acid, methyl ester & Drying oil \\
\hline $\mathrm{O} 7$ & 26.942 & Nonanedioic acid, dimethyl ester & Drying oil \\
\hline P8 & 27.804 & N-Methyl-2-pyrrolidone-5-carboxylic acid methyl ester & Animal glue \\
\hline P9 & & & Animal glue \\
\hline O8 & 36.961 & Hexadecanoic acid, methyl ester & Drying oil \\
\hline W1 & & & Beeswax \\
\hline O9 & 40.849 & 9,12-Octadecadienoic acid, methyl ester & Drying oil \\
\hline 010 & & & Drying oil \\
\hline W2 & 40.992 & 9-Octadecenoic acid (Z)-, methyl ester & Beeswax \\
\hline P10 & & & Animal glue \\
\hline 011 & 41.61 & Methyl stearate & Drying oil \\
\hline W3 & & & Beeswax \\
\hline W4 & 43.055 & Eicosene & Beeswax \\
\hline W5 & 45.885 & Eicosanoic acid, methyl ester & Beeswax \\
\hline W6 & 47.205 & Docosene & Beeswax \\
\hline W7 & 49.84 & Docosanoic acid, methyl ester & Beeswax \\
\hline W8 & 51.047 & Heneicosanol & Beeswax \\
\hline W9 & 52.842 & Triacosenol & Beeswax \\
\hline W10 & 53.52 & Tetracosanoic acid, methyl ester & Beeswax \\
\hline W11 & 56.38 & Hexacosanol & Beeswax \\
\hline W12 & 56.951 & Hexacosanoic acid, methyl ester & Beeswax \\
\hline W13 & 59.662 & Octacosanol & Beeswax \\
\hline
\end{tabular}

The Xevo G2-S Q-TOF-MS with MS $^{\mathrm{E}}$ mode was adopted to give high resolution mass of characteristic components of dyestuff. The extracts of reddish pigments and sappanwood were analyzed by both positive and negative mode and the results showed better sensitivity in the latter, so we chose the negative ion mode to get the data. $\mathrm{MS}^{\mathrm{E}}$ technique provided low and high collision energy MS data in just one analytical run nevertheless the ion $m / z$ of precursor and its fragments could be obtained simultaneously [26]. So we first used this mode then performed the MS/MS experiments to further confirm the target analytes and the data were exhibited in Table 3.
In $3.191 \mathrm{~min}, \mathrm{~m} / z 303.0866$ was found and the empirical formula was assigned as $\mathrm{C}_{16} \mathrm{H}_{16} \mathrm{O}_{6}$ with a $0.3 \mathrm{mDa}$ mass error compared to the theoretical mass 303.0869. MS/MS spectra of the extracts of reddish pigments and sappanwood as well as standard protosappanin B were well matched in Fig. 8a-c. Protosappanin B, a dibenzoxocin as a specific chemical constituent in sappanwood, was firstly discovered by Nagai et al. due to its extensive application in herbal medicine [27]. The fragmentation patterns of ions were exhibited in Additional file 3a [28, 29]. In reddish pigment extract, $m / z 285.0701$ was detected at the retention time of 3.254 min with the 


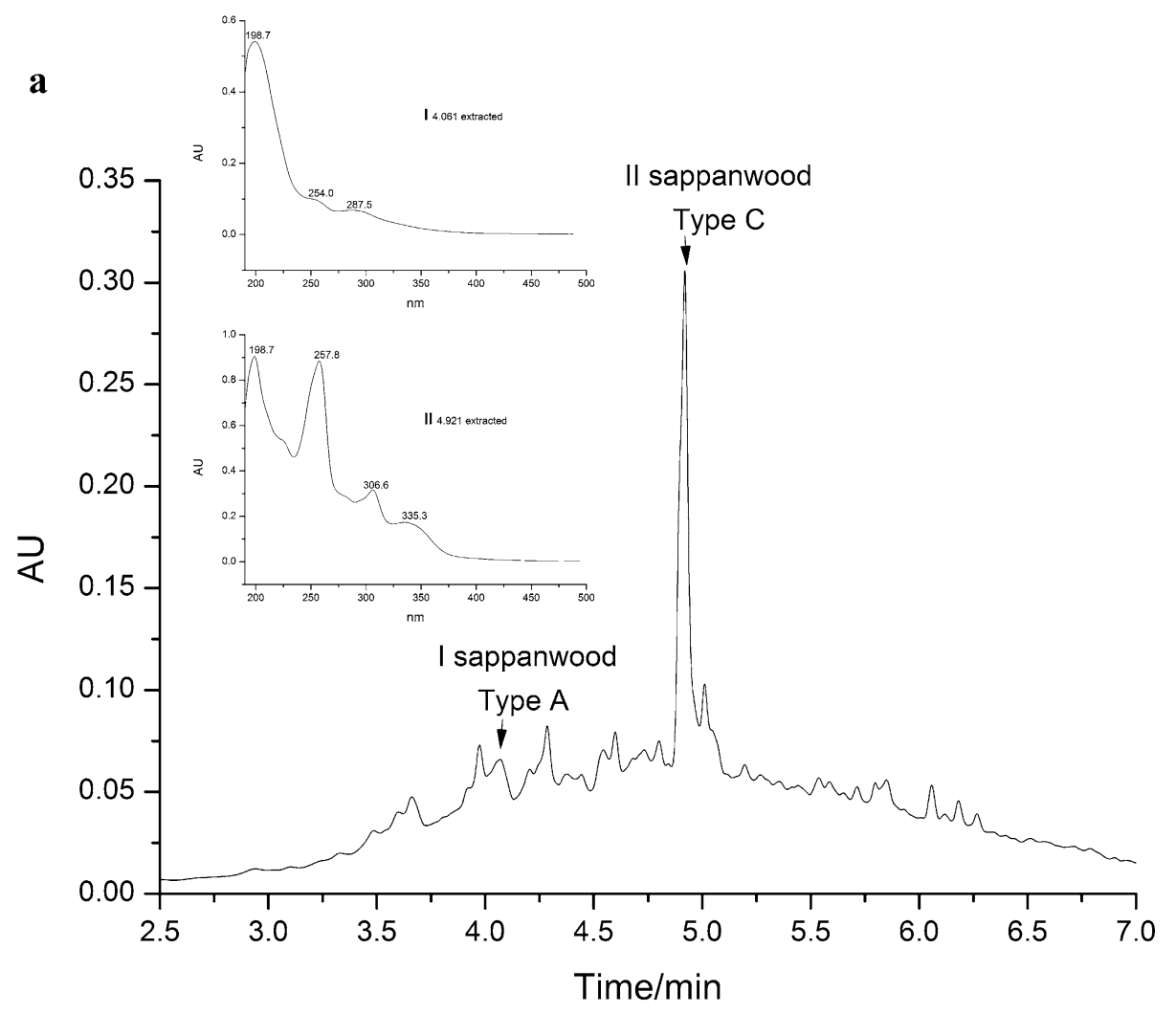

b
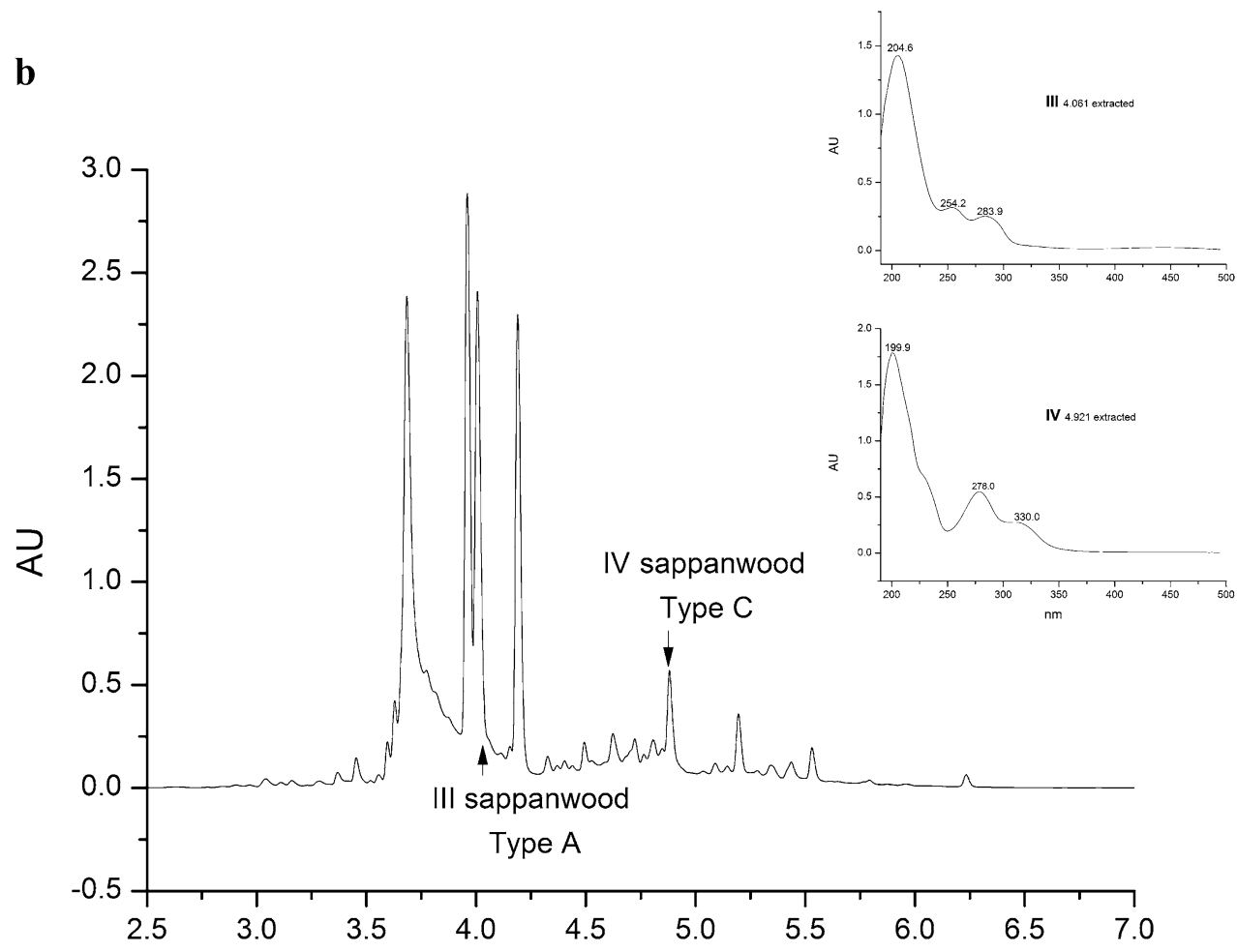

III sappanwood

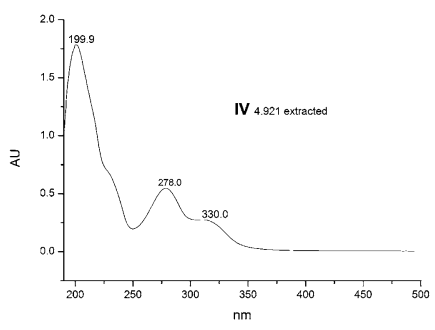

$$
\text { Type C }
$$

Type A

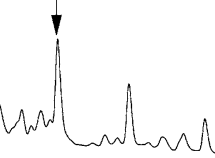


Table 3 Analysis of the extracted components from the reddish pigments

\begin{tabular}{|c|c|c|c|c|c|c|}
\hline $\mathrm{RT}$ (min) & $\begin{array}{l}\text { Measured } \\
\text { value }(m / z)\end{array}$ & $\begin{array}{l}\text { Theoretical } \\
\text { value }(\mathrm{m} / \mathrm{z})\end{array}$ & $\begin{array}{l}\text { Formula } \\
\text { and compound }\end{array}$ & High energy fragment ions & $\begin{array}{l}\text { Collision } \\
\text { energy }(\mathrm{eV})\end{array}$ & MS/MS fragment ions \\
\hline 3.191 & 303.0866 & 303.0869 & $\begin{array}{l}\mathrm{C}_{16} \mathrm{H}_{16} \mathrm{O}_{6} \\
\text { Protosappanin } \mathrm{B}\end{array}$ & $243.0229 \backslash 213.0493 \backslash 109.0250$ & $20-40$ & $\begin{array}{l}270.0533 \backslash 243.0548 \backslash 231.0620 \backslash 213.0493 \backslash 1 \\
85.0561 \backslash 159.0414 \backslash 109.0207\end{array}$ \\
\hline 3.254 & 285.0701 & 285.0763 & $\begin{array}{l}\mathrm{C}_{16} \mathrm{H}_{14} \mathrm{O}_{5} \\
\text { Brazilin }\end{array}$ & $\begin{array}{l}267.0331 \backslash 243.0357 \backslash 163.0434 \\
\backslash 121.0280\end{array}$ & $15-25$ & $\begin{array}{l}267.0598 \backslash 243.0261 \backslash 197.1108 \backslash 163.0355 \backslash 1 \\
35.0415 \backslash 121.0257\end{array}$ \\
\hline 3.889 & 283.0579 & 283.0606 & $\begin{array}{l}\mathrm{C}_{16} \mathrm{H}_{12} \mathrm{O}_{5} \\
\text { Brazilein }\end{array}$ & $265.0424 \backslash 241.0445 \backslash 109.0250$ & $20-40$ & $\begin{array}{l}265.0457 \backslash 241.0350 \backslash 240.0377 \backslash 196.0456 \backslash 1 \\
\quad 73.0529 \backslash 109.0207\end{array}$ \\
\hline
\end{tabular}

empirical formula $\mathrm{C}_{16} \mathrm{H}_{14} \mathrm{O}_{5}$. According to fractured data, brazilin was inferred and cleavage mechanism was clarified in Additional file $3 \mathrm{~b}$ according to reported literatures $[28,30]$. Moreover, MS/MS spectra of the extracts of reddish pigments and sappanwood as well as standard brazilin were well matched in Fig. 8d-f. Brazilin, as a very common component in sappanwood, was isolated by Chevreul in 1808, and a hundred years afterwards its structure was confirmed by Perkin and Robinson [25]. Protosappanin B and brazilin are the main components from sappanwood in aqueous or alcoholic extract conditions [28].

Brazilein, as the main coloring matter, was found in 3.889 min which was the oxidation product of brazilin. The measured mass was $\mathrm{m} / z 283.0579$ with a $2.7 \mathrm{mDa}$ error off the theoretical mass 283.0606. Characteristic product ions at $m / z 265.0457\left[\mathrm{M}-\mathrm{H}-\mathrm{H}_{2} \mathrm{O}\right]^{-}, 240.0377$ $\left[\mathrm{M}-\mathrm{H}-\mathrm{C}_{2} \mathrm{H}_{3} \mathrm{O}\right]^{-}, 237.0520\left[\mathrm{M}-\mathrm{H}-\mathrm{H}_{2} \mathrm{O}-\mathrm{CO}\right]^{-}, 196.0456$ $\left[\mathrm{M}-\mathrm{H}-\mathrm{C}_{3} \mathrm{H}_{3} \mathrm{O}_{3}\right]^{-}, \quad 173.0529 \quad\left[\mathrm{M}-\mathrm{H}-\mathrm{C}_{6} \mathrm{H}_{6} \mathrm{O}_{2}\right]^{-}$and $109.0207\left[\mathrm{M}-\mathrm{H}-\mathrm{C}_{10} \mathrm{H}_{6} \mathrm{O}_{3}\right]^{-}$were formed and consistently in the extracts of reddish pigments and sappanwood as well as standard brazilein (Fig. $8 \mathrm{~g}-\mathrm{i}$ ). The fragmentation mechanism was shown in Additional file 3c according to the work by Hulme et al. [31, 32]. Brazilin could be transformed into brazilein by oxidation but remained detectable due to two reasons: the oxidation reaction was inhibited in slightly acidic environment to some extent, or certain precursors could be convert into brazilin by heating or catalytic amounts of acid or base [25, 33]. Therefore, dye precursor brazilin and the oxidized brazilein were both detected in the reddish pigment extract.

Sappanwood, as a very common reddish natural dye plant, was recorded as su fang 蘇方/枋 or su fang mu 蘇方/枋木 in Chinese, whose main species was Caesalpinia sappan L. in the family Leguminosae. Sappanwood only grew in tropical regions. Its cultivation on continental China never met the demand of sappanwood in ancient China. Therefore, sappanwood was documented to have been consistently imported to Guangzhou from South East Asia via sea trade [34].The initial record dated back to Nanfang caomu zhuang (南方草木状) written by the Botanist Ji Han (稀含, 263-306 C.E.) in Jin Dynasty
(265-420 C.E.) [35]. In the early sixteenth century, the discovery of South America led to use the alternative plant Brazilwood (Caesalpinia brasiliensis L.) in Europe, which caused the trade with Asian sappanwood to decline dramatically [25]. Since both had the above discussed dyestuff chromophores [36], the identification of the specific species was a true challenge and merited further study in our future work.

The soluble redwoods included two famous genera caesalpinia and haematoxylum in both which neoflavonoids as the main coloring principle [30,33], however, there were no mass sources of the recognizable colorant haematoxylin or haematoxylein further to exclude the application of logwood in this red dyeing. Since protosappanin $\mathrm{B}$ and brazilin were colorless, the clarified coloring mechanism was speculated that brazilein was the responsible agent which formed a metal coordination complex with aluminum and produced the meta red color [37]. As a result, after verified by the high resolution MS/MS spectra of the extracts of reddish pigments and sappanwood as well as reference standards including protosappanin $\mathrm{B}$, brazilin and brazilein, the use of natural dyestuff plant sappanwood in pigment dyeing was confirmed.

\section{Proposed manufacture craft}

The components and corresponding analysis of the rough fiber paper from the lowest layer of the whole piece were listed in Table 4. Other layer paper from this piece of tie luo also utilized the same fenjian technique. According to the above results as well as combining the ancient recipes [38], the manufacture of fenjian was tentatively described as follows: the dry sappanwood was collected into the pot followed by boiling, juicing, dyeing to the white lead at the same time beeswax was added to wet the pigments and make a smooth paste. Then paint onto the paper after appropriately mixing with organic binding medium with the purpose of bonding and anchoring the pigments to paper surface. In order to hold and fix the color, proper proportion of alum gelatin solution was used. Press, smooth for creating and finally mount to the wall. 


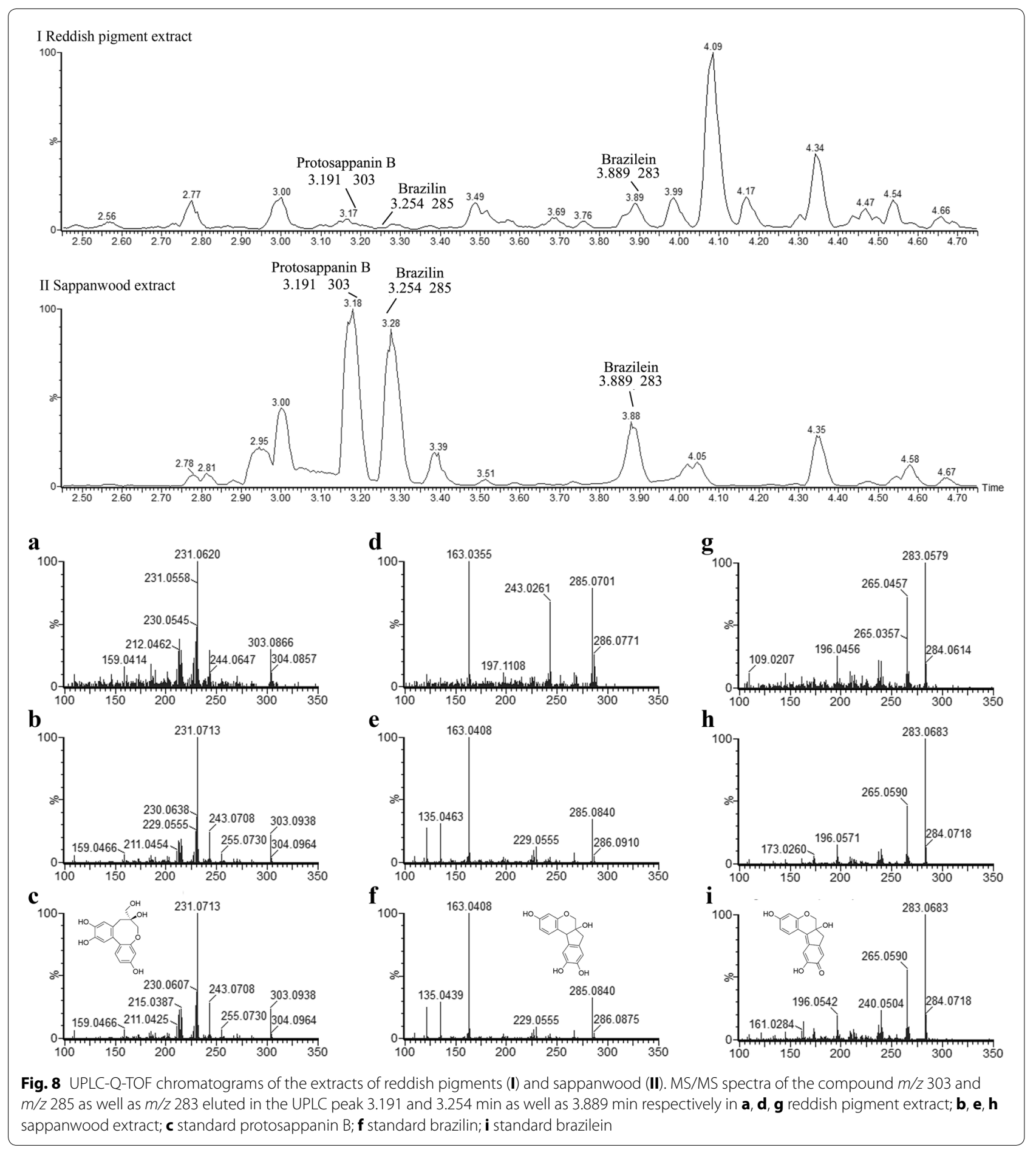

\section{Conclusions}

By the symmetrical combination of several analytical methods, the making technique of fenjian for the tie luo was assumed scientifically. The paper is made of mulberry bark fiber. And the decorative ground coating is a layer of organic reddish pigments. The pigments were mainly composed of white lead dyed by sappanwood, a natural dyestuff plant. For the binding media mixed with the pigments, a type of animal glue, drying oils and beeswax were identified. In dye analysis, protosappanin B and brazilin as well as brazilein were detected, which implied the sappanwood was used for the organic manufacture 
Table 4 The analytical methods and results of the relic sample in this article

\begin{tabular}{lll}
\hline Sample depiction & Identified results & Characterizations \\
\hline Reddish pigments & Pigments & \\
& White lead (main) & XRD \\
& Binding media & ATR-FTIR \\
& Animal glue & ATR-FTIR \\
& Drying oils & Py-GC/MS \\
& Beeswax & \\
& Organic dye & \\
& Sappanwood & UPLC-Q-TOF MS \\
& Mulberry bark & OM \\
Paper fiber & & PLM \\
& Talc, lime and clay & ATR-FTIR \\
\hline
\end{tabular}

of pigments. In addition, both Nowik type $\mathrm{A}$ and $\mathrm{C}$ were found in the research, though colorless but significant and characteristic components for sappanwood identification.

\section{Additional files}

Additional file 1. The surface (a) and back (b) of fenjian in visible light (pictured by portable Dino-Lite digital microscope).

Additional file 2. Element distribution of the fenjian detected by EDXRF.

Additional file 3. Proposed fragmentation patterns for protosappanin B (a) and brazilin (b) as well as brazilein (c) (a and b redrawn from Tong et al. c from Hulme et al. with permission from Elsevier Ltd. References were listed in the body article.).

\section{Abbreviations}

OM: optical microscopy; PLM: polarizing light microscopy; XRD: X-ray diffraction; Micro-FTIR: micro-Fourier transform infrared; ATR: attenuated total reflection; THM-Py-GC/MS: pyrolysis gas chromatography and mass spectrometry with thermal assisted hydrolysis and methylation; UPLC-Q-TOF-MS: ultraperformance liquid chromatography combined with quadrupole time-offlight mass spectrometry; PDA: photodiode array detection.

\section{Authors' contributions}

LY created the study idea and oversaw the whole work. WL conducted all the experiments including the data analysis and completed the paper. CWJ provided the representative relic sample. JGW, GZM and ZY designed and assisted the LC/MS experiment. WYL identified the paper fiber. KBQ carried out the XRD experiment. WN performed the Py-GC/MS experiment. GA analyzed the ATR-FTIR results. All authors read and approved the final manuscript.

\section{Author details}

${ }^{1}$ Conservation Department, The Palace Museum, \#4 Jingshan Qianjie, Beijing 100009, People's Republic of China. ${ }^{2}$ Key Lab of Separation Science for Analytical Chemistry, Dalian Institute of Chemical Physics, Chinese Academy of Sciences, Dalian 116023, People's Republic of China.

\section{Acknowledgements}

This work is financially supported by the Foundation for Outstanding Young Scholars in Conservation Science and Technology (Grant No. 2015-302) and The Palace Museum research project (KT 2015-14). We would like to thank our colleague Mr. Li Yu for historical literature research. We are also grateful to Dr. Jing Han from Getty Conservation Institute and Prof. Zhenxia Du from Beijing University of Chemical Technology with respect to dye analysis.
Competing interests

The authors declared that they have no competing interests.

Ethics approval and consent to participate

Not applicable.

\section{Publisher's Note}

Springer Nature remains neutral with regard to jurisdictional claims in published maps and institutional affiliations.

Received: 24 January 2018 Accepted: 16 April 2018

Published online: 02 May 2018

References

1. Hunter D. Papermaking: the history and technique of an ancient craft. New York: Dover Publications; 1978. p. 496.

2. Wang $\mathrm{JH}$. The history of papermaking engineering and technology in ancient China. Taiyuan: Shanxi Education Press; 2006. p. 255 (in Chinese).

3. Yang Z ZH. The investigation and restoration of tiē luò of fú wàng gé: a case study of the writings by emperor qianlong in fú wàng gé (tower of elusive dreams). Palace Museum J. 2015;3:136-62 (in Chinese).

4. Zhao EX. Qing shi gao. Beijing: Zhonghua shuju; 1977. p. 11574 (in Chinese).

5. Van Beek HCA, Heertjes PM. Fading by light of organic dyes on textiles and other materials. Stud Conserv. 1966;11(3):123-32.

6. Puchtler H, McGowan AL, Meloan SN. Why do some stains fade? Part II. Effects of dye structure, molecular-orbital systems, metals, substrates, moisture, and chemical-reactions. J Histotechnol. 1989;12(2):129-34.

7. Shi JL, LiT. Technical investigation of 15 th and 19th century Chinese paper currencies: fiber use and pigment identification. J Raman Spectrosc. 2013:44(6):892-8.

8. Wouters J, Grzywacz CM, Claro A. A comparative investigation of hydrolysis methods to analyze natural organic dyes by HPLC-PDA. Stud Conserv. 2011;56(3):231-49.

9. Lei Y, Wang SW. Material analysis of the wall painting in Xialu Temple, Tibet Autonomous Region, China. Stud Conserv. 2014;59(5):314-27.

10. Wang $\mathrm{JH}$. Papermaking raw materials of China: an atlas of micrographs and the characteristics of fibers. Beijing: China Light Industry Press; 1999. p. 172-8 (in Chinese).

11. Gettens RJ, Kuhn H, Chase WT. Lead White. In: Ashok R, editor. Artists' pigments: a handbook of their history and characteristics. New York: Oxford University Press; 1993. p. 67-81.

12. Sotiropoulou S, Daniilia S, Miliani C, Rosi F, Cartechini L, PapanikolaBakirtzis D. Microanalytical investigation of degradation issues in Byzantine wall paintings. Appl Phys A. 2008;92:143-50.

13. De Benedetto GE, Fico D, Margapoti E, Pennetta A, Cassiano A, Minerva B. The study of the mural painting in the 12th century monastery of Santa Maria delle Cerrate (Puglia-Italy): characterization of materials and techniques used. J Raman Spectrosc. 2013;44(6):899-904.

14. Zhou GX. Lead-containing pigments in ancient murals and polychrome sculptures from the northwest China. Sci Conserv Archaeol. 2012;24(1):95-103 (in Chinese)

15. Vera QM, Marcella L, Armida S, Franco PG, Daila R. A seventeenth century Japanese painting: scientific identification of materials and techniques. Stud Conserv. 2014;59(5):328-40.

16. Ma Y, Lei Y, Wang SW. The component and craftwork analysis of the wallpapers of yucui xuan (pavilion) of the Forbidden City. Palace Museum J. 2017;1:154-9 (in Chinese)

17. Gonzalez V, Gourier D, Calligaro T, Toussaint K, Wallez G, Menu M. Revealing the origin and history of lead-white pigments by their photoluminescence properties. Anal Chem. 2017;89(5):2909-18.

18. Kovala-Demertzi D, Papathanasis L, Mazzeo R, Demertzis MA, Varella EA, Prati S. Pigment identification in a Greek icon by optical microscopy and infrared microspectroscopy. J Cult Herit. 2012;13:107-13.

19. Derrick MR, Stulik D, Landry JM. Infrared spectroscopy in conservation science. Los Angeles: The Getty Conservation Institute; 1999. 
20. Serefidou M, Bracci S, Tapete D, Andreotti A, Biondi L, Colombini MP, et al. Microchemical and microscopic characterization of the pictorial quality of egg-tempera polyptych, late 14th century, Florence, Italy. Microchem J. 2016;127:187-98.

21. Schilling MR, Heginbotham A, Van Keulen H, Szelewski M. Beyond the basics: a systematic approach for comprehensive analysis of organic materials in Asian lacquers. Stud Conserv. 2016;61(S3):3-27.

22. Bonaduce I, Colombini MP. Characterisation of beeswax in works of art by gas chromatography-mass spectrometry and pyrolysis-gas chromatography-mass spectrometry procedures. J Chromatogr A. 2004;1028:297-306.

23. Wei SY, Song GD, He YL. The identification of binding agent used in late Shang Dynasty turquoise-inlayed bronze objects excavated in Anyang. $J$ Archaeol Sci. 2015;59:211-8

24. Han J. The historical and chemical investigation of dyes in high status chinese costume and textiles of the Ming and Qing Dynasties (1368-1911). PhD thesis. Glasgow: University of Glasgow; 2016.

25. Nowik W. The possibility of differentiation and identification of red and blue 'soluble' dyewoods: determination of species used in dyeing and chemistry of their dyestuffs. In: Kirby J, editor. Dyes history archaeol. London: Archetype Publications; 2001. p. 129-44.

26. Zhang LY, Tian KX, Wang YL, Zou JX, Du ZX. Characterization of ancient chinese textiles by ultra-high performance liquid chromatography/ quadrupole-time of flight mass spectrometry. Int J Mass Spectrom. 2017:421:61-70.

27. Nagai M, Nagumo S, Protosappanin B. a new dibenzoxocin derivative from sappan lignum. Heterocycles. 1986;24(3):601-5.

28. Tong XZ, Zhu H, Shi Y, Xu HT, Wang B, Zhao JH. An LC/MS/MS method for simultaneous quantitation of two homoisoflavones: protosappanin $B$ and brazilin with hypoglycemic activity in rat plasma and its application to a comparative pharmacokinetic study in normal and streptozotocintreated rats. J Ethnopharmacol. 2013;148(2):682-90.

29. Zhang LY, Tian KX, Wang YL, Du ZX. Characterization of natural dyes in ancient red textiles of the Qing Dynasty by ultra-high performance liquid chromatography-quadrupole-time of flight-mass spectrometry. J Beijing U Chem Technol (Nat Sci). 2017;44(5):52-7 (in Chinese).

30. Rosenberg E. Characterisation of historical organic dyestuffs by liquid chromatography-mass spectrometry. Anal Bioanal Chem. 2008;391(1):33-57.

31. Hulme AN, McNab H, Peggie DA, Quye A. Negative ion electrospray mass spectrometry of neoflavonoids. Phytochemistry. 2005;66(23):2766-70.

32. Zhao S, Wang XP, Jiang JF, Chai YS, Tian Y, Feng TS, et al. Transport and metabolism behavior of brazilein during its entrance into neural cells. PLoS ONE. 2014;9(10):e108000.

33. Cardon D. Natural dyes: sources, tradition, technology and science. London: Archetype; 2007.

34. Han J. Botanical provenance of historical chinese dye plants. Econ Bot. 2015;69(3):230-9.

35. National Bureau of Traditional Chinese medicine, Chinese Materia Medica Editorial Board. Chinese Materia Medica. Shanghai: Shanghai Science and Technology Press; 1999. p. 3014 (in Chinese).

36. Ferreira ESB, Hulme AN, McNab H, Quye A. The natural constituents of historical textile dyes. Chem Soc Rev. 2004;33:329-36.

37. Dapson R, Bain C. Brazilwood, sappanwood, brazilin and the red dye brazilein: from textile dyeing and folk medicine to biological staining and musical instruments. Biotech Histochem. 2015;90(6):401-23.

38. Liu J. Many abilities in humble activities. Shanghai: Shanghai Classics Publishing House; 1996 (in Chinese).

\section{Submit your manuscript to a SpringerOpen ${ }^{\circ}$ journal and benefit from:}

- Convenient online submission

- Rigorous peer review

- Open access: articles freely available online

- High visibility within the field

- Retaining the copyright to your article

Submit your next manuscript at $\boldsymbol{\nabla}$ springeropen.com 